\title{
Obstetric management of the next pregnancy after an unexplained stillbirth: An anonymous postal survey of Australian obstetricians
}

\author{
Stephen ROBSON, ${ }^{1}$ Jane THOMPSON ${ }^{2}$ and David ELLWOOD ${ }^{1}$ \\ ${ }^{1}$ Australian National University Medical School and ${ }^{2}$ Clinical Health Improvement Program, The Canberra Hospital, Canberra, Australia
}

\begin{abstract}
Background: Women who have an unexplained stillbirth are more likely to be delivered early, by induced labour or Caesarean section, in their next pregnancy. It is unclear whether these birth outcomes result from characteristics of the next pregnancy, or represent management strategies of obstetricians.

Aim: To investigate obstetricians' management strategies in the next pregnancy after an unexplained stillbirth.

Methods: Anonymous postal survey of Australian obstetricians. Respondents were given a clinical scenario regarding a previous unexplained stillbirth and were asked about management.

Results: The response rate was $69 \%$. Tests of 'fetal well-being' were undertaken by the majority of respondents. Additional third trimester ultrasound surveillance was recommended by $87 \%$ of respondents, regular cardiotograph monitoring by $72 \%$ and formal fetal movement charting by $39 \%$. Elective induction of labour (in the absence of any other obstetric indication) was recommended by $93 \%$ of respondents, and elective Caesarean delivery by $35 \%$.

Conclusions: The tendency for subsequent pregnancies after an unexplained stillbirth to be delivered earlier, and more often by Caesarean section, may be due in part to altered management strategies, not solely as a result of complications of the pregnancy itself.
\end{abstract}

Key words: Caesarean section, cardiotocograph, fetal movements, non-stress test, unexplained stillbirth.

\section{Introduction}

The unexpected loss of a baby during the latter part of pregnancy is a calamity for a woman and her family. In Australia, approximately one in 200 pregnancies ends in stillbirth, of which up to $25 \%$ are classified as unexplained. ${ }^{1-3}$ This figure is similar to the rate of unexplained stillbirth in other countries of the developed world. ${ }^{4-6}$

A question commonly asked by women after stillbirth is, 'What are the chances of this happening again in my next pregnancy?' If no consideration is made of the aetiology of the stillbirth, they face an empirical 10-fold increase in the risk of stillbirth in subsequent pregnancies, as well as increased risks of both medical complications (such as hypertension and diabetes) and adverse neonatal outcomes. ${ }^{7}$ However, the prognosis varies according to the aetiology of the stillbirth. For example, if the stillbirth resulted solely from placental causes, there is an increased risk of placental abruption and preterm birth in the next pregnancy. ${ }^{8}$ When the stillbirth remains unexplained, though, providing a woman with prognostic information for her next pregnancy is more difficult. Prognostic data are limited, and the largest study of pregnancy outcome after an unexplained stillbirth found that the risk of stillbirth in the next pregnancy after unexplained stillbirth was no higher than that of the general population. ${ }^{9}$ However, those subsequent pregnancies ended earlier than matched controls, and the issue of a management bias remains unresolved.

Management of the next pregnancy after an unexplained stillbirth causes great anxiety in women, their partners and families, and indeed their obstetric carers. ${ }^{10}$ While the available evidence suggests that perinatal outcomes in subsequent pregnancies are not necessarily compromised, it remains unclear as to whether this might result from greater vigilance and a low threshold for intervention rather than the biology of the pregnancy itself. We sought to answer the question: Are the subsequent pregnancies of women who have suffered an unexplained stillbirth managed differently from those of other women? To do this, we undertook a survey of Australian

Correspondence: Dr Steve Robson, Department of Obstetrics and Gynaecology, The Canberra Hospital, PO Box 11, Woden, ACT 2606, Australia. Email: steve.robson@act.gov.au

DOI: 10.1111/j.1479-828X.2006.00591.x

Received 06 December 2005; accepted 27 February 2006. 
Table 1 For the 334 respondents (72.4\%) recommending regular non-stress test (cardiotograph) monitoring, the gestation at commencement, and frequency of cardiotographs

\begin{tabular}{lcccc}
\hline Gestation at commencement & Weekly & $2 \times /$ week & Frequency & Total \\
\hline Before 34 weeks & $64(19.2 \%)$ & $43(12.9 \%)$ & $3(0.9 \%)$ & $110(32.9 \%)$ \\
34 weeks & $69(20.7 \%)$ & $61(18.3 \%)$ & $4(1.2 \%)$ & $134(40.1 \%)$ \\
35 weeks & $10(3.0 \%)$ & $20(6.0 \%)$ & $3(0.9 \%)$ & $33(9.9 \%)$ \\
36 weeks & $22(6.6 \%)$ & $28(8.4 \%)$ & $3(0.9 \%)$ & $53(15.9 \%)$ \\
37 weeks & $2(0.6 \%)$ & $2(0.6 \%)$ & 0 & $4(1.2 \%)$ \\
After 37 weeks & 0 & 0 & 0 & 0 \\
\hline
\end{tabular}

obstetricians, addressing their management of subsequent pregnancy after an unexplained stillbirth.

\section{Methods}

During February of 2004, an anonymous questionnaire was sent to Fellows of the Royal Australian and New Zealand College of Obstetricians and Gynaecologists (RANZCOG) with a practice address in Australia. The distribution list was provided by the RANZCOG. The questionnaire was piloted at The Canberra Hospital prior to distribution, and was sent with a reply paid envelope. The project received approval from the Human Research Ethics Committee of the Australian National University, and was thereafter approved for distribution by the Continuing Professional Development Committee of the RANZCOG. The questionnaire collected basic demographic information, and presented the following scenario:

A 25-year-old woman presents to you at 8 weeks gestation in her second pregnancy. Her first pregnancy, two years ago, had been totally normal until occurrence of an unexplained intrauterine fetal death at 37 weeks. Induction of labour led to vaginal delivery of a normally grown fetus. Full investigation, including specialised perinatal autopsy, yielded absolutely no cause for the fetal death. She is otherwise healthy and no specific medical or gynaecological problems have manifest since. Considering the management of this current pregnancy, please indicate the management you would undertake.

A series of questions was presented regarding management of such a pregnancy, with regard to investigations and treatments including method of delivery.

\section{Results}

A total of 702 questionnaires were posted, and 486 were returned (a response rate of $69 \%$ ). Four respondents indicated that they no longer practised obstetrics, and a further 14 surveys were incomplete, leaving 468 surveys suitable for analysis.

\section{Management of the first half of pregnancy}

All 468 respondents (100\%) indicated that they would arrange an ultrasound examination for fetal morphology between 18 and 20 weeks of gestation. In addition, 418 $(89 \%)$ would offer first trimester screening by nuchal translucency (with or without associated biochemical screening, for example with PAPP-A), and 410 (88\%) would arrange early ultrasound to confirm gestational age. One hundred and thirty-five respondents $(29 \%)$ stated that they would undertake testing for diabetes before 20 weeks gestation, and $72(15 \%)$ would perform other investigations: thrombophilia screening (10\%); screening for antiphospholipid syndrome (7\%); autoantibody screening (5\%); testing for chronic infections $(2 \%)$; thyroid function testing (1\%); and other tests (2\%). Referral for additional counselling and support was advocated by 135 respondents (29\%).

\section{Management of the latter half of the pregnancy}

Formal fetal movement charting was advocated by 183 respondents (39\%). Of these, $116(25 \%)$ would initiate such 'kick counting' before 34 weeks of gestation, the remainder by 36 weeks. Surveillance with antenatal cardiotocograph (CTG) monitoring ('non-stress testing') would be initiated by 334 respondents (72\%). The gestation at which CTG monitoring would be commenced, and the frequency of the tests, is presented in Table 1. Ultrasound surveillance (for fetal growth, amniotic fluid volume, and/or Doppler cord flow assessment) was advocated by 409 respondents (87\%). The gestation at which ultrasound monitoring would be commenced, and the frequency of the tests, is presented in Table 2.

\section{Management of labour and delivery}

When asked, 'In the absence of any other obstetric indication, would you offer this woman elective induction of labour?' 436 respondents (93\%) indicated they would. Of these, $56(12 \%)$ would offer induction 1 week before the gestation of the previous stillbirth (that is, 36 weeks), and $101(22 \%)$ would offer it at the same gestation as the stillbirth (37 weeks). For the remainder, $176(38 \%)$ would offer induction of labour at 38 weeks, $54(12 \%)$ at 39 weeks, 48 $(10 \%)$ at the due date, and $1(1 \%)$ after 40 weeks.

In response to the question 'In the absence of any other obstetric indication, would you offer this woman elective caesarean delivery?' 164 respondents (35\%) answered that they would. Of these, $26(6 \%)$ would offer Caesarean delivery 
Table 2 For the 409 respondents (87.4\%) recommending regular ultrasound surveillance, the duration at commencement, and frequency of those ultrasounds

\begin{tabular}{|c|c|c|c|c|c|}
\hline \multirow[b]{2}{*}{ Gestation at commencement } & \multicolumn{5}{|c|}{ Frequency } \\
\hline & 4 weekly & 3 weekly & 2 weekly & weekly & Total \\
\hline Before 21 weeks & $1(0.2 \%)$ & 0 & $1(0.2 \%)$ & 0 & $2(0.5 \%)$ \\
\hline 21-24 weeks & $11(2.7 \%)$ & 0 & $1(0.2 \%)$ & 0 & $12(2.9 \%)$ \\
\hline 25-28 weeks & $121(29.6 \%)$ & $25(6.1 \%)$ & $34(8.3 \%)$ & $2(0.5 \%)$ & $182(44.5 \%)$ \\
\hline 29-32 weeks & $39(9.5 \%)$ & $41(10.0 \%)$ & $61(14.9 \%)$ & $3(0.7 \%)$ & $144(35.2 \%)$ \\
\hline 33-36 weeks & $15(3.7 \%)$ & $5(1.2 \%)$ & $43(10.5 \%)$ & $6(1.5 \%)$ & $69(16.9 \%)$ \\
\hline After 36 weeks & 0 & 0 & 0 & 0 & \\
\hline
\end{tabular}

1 week before the gestation of the previous stillbirth, and $35(8 \%)$ would offer it at the same gestation. For the remainder, $70(15 \%)$ would offer Caesarean delivery at 38 weeks, 30 $(6 \%)$ at 39 weeks, and $3(1 \%)$ at term.

\section{Discussion}

In our previous case-control study, we compared the outcomes of 316 subsequent births in women who had suffered an unexplained stillbirth to 3160 births in matched controls. ${ }^{9}$ That study remains the largest published study that specifically addressed the question of prognosis after unexplained stillbirth. We found that the women who had an unexplained stillbirth did not have increased odds of stillbirth or perinatal death in subsequent pregnancy. That study did find a fourfold increase in the odds of diabetes being diagnosed in the subsequent pregnancy, compared to matched controls. Interestingly, increases were found in the odds for induced labour, Caesarean delivery and preterm birth. As well, the gestational age at birth in the next pregnancy after unexplained stillbirth was significantly earlier than the control group. However, it was unclear whether changes in the pattern of induction of labour, mode of delivery and gestation at birth represented a response to complications of the pregnancy, or resulted from a systematic change in the way obstetricians managed subsequent pregnancies after a history of unexplained stillbirth - a management bias.

The results of our survey may help to answer this question. The scenario presented to the surveyed obstetricians was of a young woman who had suffered a near-term stillbirth, where the fetus was not growth restricted, and for which no maternal or placental cause could be found. In light of the results of our previous work, ${ }^{9}$ there is a low risk of adverse outcome in her next pregnancy. Aside from repeating tests for conditions that might predispose to stillbirth (lupus obstetric syndrome, for example), the majority of respondents proposed management strategies for the first half of pregnancy that were little different from routine antenatal management practices in low-risk pregnancy. However, there was great diversity in the managements proposed for the latter half of the pregnancy. This was reflected in terms of varying forms of 'monitoring for fetal well-being', with fetal movement charting, CTG (non-stress test) and ultrasound surveillance advocated by most respondents. As well, recommendations for induced and Caesarean delivery, often advocated before the due date, were clearly at variance with generally accepted guidelines. ${ }^{11}$

With appropriate investigation, the cause of most stillbirths can be determined. ${ }^{4-6,12-14}$ If aetiology of fetal death is disregarded, it is clear that, as a group, women who have had a previous stillbirth face an increased risk of adverse outcomes in future pregnancies. ${ }^{5,7}$ However, the available data suggest that the subset of women whose stillbirth was unexplained may not face increased risks of adverse outcome in the next pregnancy. ${ }^{9}$ If that is truly the case, then increased surveillance by fetal movement counting, CTG (non-stress test) or ultrasound surveillance would be expensive, potentially stressful, and would confer no benefit. ${ }^{15-17}$ However, basing such an assessment of risk on retrospective data from a case-control study could be flawed on at least two grounds. First, maternal anxiety and stress alone (as are likely to occur in the next pregnancy after a stillbirth) are themselves associated with adverse neonatal outcomes. ${ }^{18}$ Second, the limited epidemiological evidence on which our estimates of risk are based could be misleading, because subsequent birth outcomes might be little different from other pregnancies because of increased surveillance, with obstetricians having a low threshold to intervene in the next pregnancy.

These are very important issues to clarify, because monitoring and liberal use of induction of labour and Caesarean delivery are not necessarily benign interventions. ${ }^{19,20}$ Indeed, there is evidence that Caesarean delivery and preterm birth may increase the risk of stillbirth in the next pregnancy. ${ }^{21,22}$

The other factor that remains largely unstudied is that of women's wishes for management of their next pregnancy after an unexplained stillbirth. It might be that the higher rates of obstetric intervention in the next pregnancy after stillbirth reflect the preferences of the women themselves. Whether intensive pregnancy surveillance increases or decreases women's and their family's levels of anxiety, and desire for intervention or otherwise, is presently unknown.

\section{Conclusion}

Obstetricians' management of the next pregnancy after an unexplained stillbirth is variable, with many clinicians recommending close surveillance and early delivery, and others advocating management little different from routine low-risk 
antenatal care. This survey suggests that the reassuring subsequent pregnancy outcomes documented in our retrospective study ${ }^{9}$ might actually be influenced by increased levels of surveillance, and a low threshold for intervention. It remains unclear whether the pregnancy after unexplained stillbirth should be considered 'high risk', and there are few guidelines for management to guide clinicians. These issues are unlikely to be resolved without a large prospective study that provides data on obstetricians and women's preferences.

\section{References}

1 Gee V, Green T. Perinatal statistics in Western Australia, 2003. Twenty-first Annual Report of the Western Australian Midwives' Notification System. Perth, Western Australia: Department of Health, 2004.

2 Laws P, Sullivan E. Australia's mothers and babies 2002. AIHW Cat. No. PER 28. 2004; Sydney: AIHW National Perinatal Statistics Unit (Perinatal Statistics Series No. 15).

3 The Consultative Council on Obstetric and Paediatric Mortality and Morbidity. Annual report for the year 2003, incorporating the 42nd Survey of Perinatal Deaths in Victoria, 2004. Melbourne: The Consultative Council on Obstetric and Paediatric Mortality and Morbidity.

4 Froen JF, Arnestad M, Frey K, Vege A, Saugstad OD, StrayPedersen B. Risk factors for sudden intrauterine unexplained death: epidemiologic characteristics of singleton cases in Oslo, Norway, 1986-95. Am F Obstet Gynecol 2001; 184: 694.

5 Goldenberg RL, Kirby R, Culhane JF. Stillbirth: a review. F Matern Fetal Neonatal Med 2004; 16: 79.

6 Huang DY, Usher RH, Kramer MS, Yang H, Morin L, Fretts RC. Determinants of unexplained antepartum fetal deaths. Obstet Gynecol 2000; 95: 215.

7 Samueloff A, Xenakis EM, Berkus MD, Huff RW, Langer O. Recurrent stillbirth. Significance and characteristics. F Reprod Med 1993; 38: 883.

8 Heinonen S, Kirkinen P. Pregnancy outcome after previous stillbirth resulting from causes other than maternal conditions and fetal abnormalities. Birth 2000; 27: 33.

9 Robson S, Chan A, Keane RJ, Luke CG. Subsequent birth outcomes after an unexplained stillbirth: preliminary populationbased retrospective cohort study. Aust NZ F Obstet Gynaecol 2001; 41: 29.

10 Ong S, Danielian P. Unexplained stillbirths: are they preventable? Int f Gynaecol Obstet 2000; 69: 159.

11 Royal College of Obstetricians and Gynaecologists (RCOG). Induction of labour. Evidence-based Clinical Guideline No. 9. 2001; RCOG Press.

12 Dodd JM, Robinson JS, Crowther CA, Chan A. Stillbirth and neonatal outcomes in South Australia, 1991-2000. Am f Obstet Gynecol 2003; 189: 1731.

13 Froen JF, Gardosi JO, Thurmann A, Francis A, StrayPedersen B. Restricted fetal growth in sudden intrauterine unexplained death. Acta Obstet Gynecol Scand 2004; 83: 801.

14 Incerpi MH, Miller DA, Samadi R, Settlage RH, Goodwin TM. Stillbirth evaluation: what tests are needed? Am $\mathcal{F}$ Obstet Gynecol 1998; 178: 1121.

15 Bricker L, Neilson JP. Routine ultrasound in late pregnancy (after 24 weeks gestation). Cochrane Database Syst Rev 2000; (2): CD001451.

16 Harrington $\mathrm{K}$, Thompson O, Jordan L et al. Obstetric outcome in women who present with a reduction in fetal movements in the third trimester of pregnancy. F Perinat Med 1998; 26: 77.

17 Pattison N, McCowan L. Cardiotocography for antepartum fetal assessment. Cochrane Database Syst Rev 2000; (2): CD001068.

18 Misri S, Oberlander TF, Fairbrother N et al. Relation between prenatal maternal mood and anxiety and neonatal health. Can F Psychiatry 2004; 49: 684.

19 Boulvain M, Marcoux S, Bureau M, Fortier M, Fraser W. Risks of induction of labour in uncomplicated term pregnancies. Paediatr Perinat Epidemiol 2001; 15: 131.

20 Van Gemund N, Hardeman A, Scherjon SA, Kanhai HH. Intervention rates after elective induction of labor compared to labor with a spontaneous onset. A matched cohort study. Gynecol Obstet Invest 2003; 56: 133.

21 Smith GC, Pell JP, Dobbie R. Caesarean section and risk of unexplained stillbirth in subsequent pregnancy. Lancet 2003; 364: 1779.

22 Surkan P, Stephansson O, Dickman P, Cnattingius S. Previous preterm and small-for-gestational-age births and the subsequent risk of stillbirth. N Engl F Med 2004; 350: 777. 